\title{
Desempenho e resposta imune de frangos de corte alimentados com dietas suplementadas com cromo na forma orgânica*
}

\author{
Immune response and performance by broiler chickens dietary \\ supplemented with chromium in organic form
}

Sandra Regina Gomes da Silva, ${ }^{* *}$ Marvio Lobão Teixeira de Abreu, ${ }^{* *}$ João Batista Lopes, ${ }^{* *}$ Daniel Irineu Brandão Leal, ${ }^{* *}$ Snaylla Natyelle de Oliveira Almendra, ${ }^{* *}$ Silvana Maria Medeiros de Sousa Silva, ${ }^{* * *}$ Elvania Maria da Silva Costa**

\begin{abstract}
Resumo
O experimento foi conduzido com o objetivo de avaliar o efeito da suplementação de cromo-orgânico, sobre o desempenho, biometria dos órgãos digestivos e linfoides, histomoformetria da bolsa cloacal e rendimento de carcaça e cortes nobres de frangos de corte de 1 a 41 dias de idade, naturalmente submetidos a estresse por calor cíclico. Foram utilizados 400 pintos de corte da linhagem Cobb, em um delineamento experimental inteiramente casualizado, com cinco tratamentos: 0; 350; 700; 1050 e 1400 ppb de cromo na ração. Os valores do índice de temperatura de globo e umidade foram, respectivamente, 83,39 e 80, para fase de crescimento e terminação. A suplementação do cromo orgânico influenciou $(P<0,01)$ de forma quadrática a conversão alimentar dos animais segundo a equação $Y=1,67-0,00016 x+0,00000012 x^{2}\left(r^{2} 0,976\right)$, na fase de 1 a 21 dias de idade. Os níveis de suplementação do cromo orgânico proporcionaram melhor índice de eficiência produtiva e maior percentual de parênquima cortical nas aves aos 21 dias. Na fase de 1 a 41 dias de idade, verificou-se que o peso de penas foi influenciado positivamente com os níveis de cromo orgânico e que não houve efeito para o desempenho dos frangos. Conclui-se que a suplementação da ração com cromo orgânico melhora desempenho e a resposta imune de frangos de corte frente a condições de estresse por calor.
\end{abstract}

Palavras-chave: avicultura, bolsa cloacal, estresse térmico, órgãos linfoides.

\begin{abstract}
This study was conducted to evaluate the effect of adding organic chromium dietary supplementation on performance, digestive and lymphoid organs biometry and histomorphometry of the clocal bursa and on carcass and prime cuts performance of broilers from 1 to 41 days old, naturally stressed by heat cyclic. We used 400 chicks Cobb, the experimental design adopted was a completely randomized, with five treatments: 0; 350; 700; 1050 and $1400 \mathrm{ppb}$ chromium in diet. The supplementation with organic chromium influenced $(p<0,01)$ quadratic form on alimentary conversion the animals according to the equation $Y=1.67$ to $0.00016 \times 0.00000012 \mathrm{x}^{2}\left(\mathrm{r}^{2} 0.976\right)$ in the period 1 to 21 . The levels of supplementation of organic chromium improvement productive efficiency and percentage of cortical parenchyma of broilers to 21 days. In phase to 1 from 41 days old, it was observed improvement the feathers weight with levels of organic chromium, and there wasn't influence on performance of broilers. The chromium in the organic form improves the performance of broiler chickens and immune response by broiler chickens in cyclic heat stress.
\end{abstract}

Keywords: aviculture, bursa of Fabricius, stress by heat, lymphoid organs.

\section{Introdução}

As condições climáticas de regiões tropicais têm interferido negativamente na produtividade e na qualidade da criação de frangos de corte devido às altas temperaturas, que é o fator físico que mais afeta o desempenho desses animais. Quando as aves estão em situações de estresse térmico, suas funções metabólicas são alteradas, o que prejudica o funcionamento do sistema imune destes animais (Ribeiro, 2008).

O sistema imune nas aves funciona de maneira semelhante ao dos mamíferos, embora a estrutura e diferenciação dos órgãos linfoides nas aves apresentem diferenças marcantes. O timo e a bolsa cloacal são responsáveis pelos mecanismos de imunidade adquirida, ambos os órgãos dão origem às células do sistema imune (Tanyolaç, 1993). A resposta imune das aves pode ser modulada pelas características da dieta, ou seja, pequenas alterações nos níveis nutricionais ou de ingredientes usados podem tornar a ave mais ou menos susceptível a doenças.

$\mathrm{Na}$ definição das estratégias para minimizar as perdas decorrentes do estresse por calor, destaca-se a suplementação da ração com minerais e vitaminas. A suplementação com cromo tem efeito positivo no crescimento e na eficiência alimentar de aves sob condições de estresse ambiental (Sahin et al., 2001). O principal papel do cromo no metabolismo é potencializar a

*Recebido em 11 de abril de 2014 e aceito em 13 de setembro de 2014.

**Universidade Federal do Piauí-UFPI, Departamento de zootecnia, Teresina, PI, Brasil.

***Universidade Federal de Lavras-UFLA, Departamento de zootecnia, Lavras, MG, Brasil.

****Universidade Federal do Piauí-UFPI, Departamento de clínica e cirurgia, Teresina, PI, Brasil.

Autor para correspondência e-mail: sandravet2006@hotmail.com. 
ação da insulina por sua presença na molécula organometálica, chamada fator de tolerância à glicose (Sahin et al., 2003). O metabolismo da insulina influencia na peroxidação de lipídios, e o cromo, como um cofator da insulina, age como antioxidante. O cromo, assim como algumas vitaminas, é usado nas dietas de frangos devido aos seus benefícios com relação à melhora no desempenho produtivo e resposta imune de animais submetidos a altas ou baixas temperaturas (Sahin et al., 2001).

Objetivou-se avaliar o efeito da suplementação de níveis de cromo, na forma orgânica, na dieta de frangos de corte, sobre o desempenho, a biometria de órgãos digestivos e coração, rendimento de cortes nobres e peso de penas de aves de 1 a 41 dias de idade, e a biometria dos órgãos linfoides nas aves de 1 a 21 e de 1 a 41 dias de idade e a histomorfometria da bolsa cloacal de frangos de corte estressados por calor.

\section{Material e métodos}

O experimento foi conduzido no setor de avicultura do Departamento de Zootecnia (DZO) do Centro de Ciências Agrárias (CCA) da Universidade Federal do Piauí (UFPI), em Teresina. Foram utilizados 400 pintos da linhagem Cobb, machos. Este experimento foi aprovado pelo comitê de ética da Universidade Federal do Piauí, número do cadastro, CCA012/2008.

O delineamento experimental adotado foi o inteiramente casualizado, com cinco tratamentos e quatro repetições, sendo vinte aves por unidade. Foram utilizadas duas rações basais, formuladas à base de milho e farelo de soja, suplementadas com vitaminas e minerais, de forma a atender as exigências nutricionais das aves, nas fases de crescimento (1 a 21 dias de idade) e terminação (22 a 41 dias de idade), segundo Rostagno et al. (2000). Os tratamentos consistiram na suplementação das rações basais com 0,00; 350; 700; 1050 e 1400 ppb de cromometionina $(0,1 \%$ de $\mathrm{Cr}$ no produto) em substituição ao material inerte (caulim).

As variáveis ambientais foram medidas diariamente para obtenção do Índice de Temperatura do Globo e Umidade (ITGU). Posteriormente, foi calculado o ITGU para caracterização ambiental, segundo Buffigton et al. (1981).

O consumo de ração no período de 1 a 21 e 1 a 41 dias de idade foi calculado pela diferença entre a quantidade de ração fornecida no início e o fim do período experimental, levando-se em consideração as sobras das rações. Para determinar o ganho de peso, as aves foram pesadas no início e no final de cada fase. A partir dos dados de consumo de ração e de ganho de peso, foi calculada a conversão alimentar dos animais.

A viabilidade criatória (VIC) e o índice de eficiência produtiva (IEP) foram calculados segundo as fórmulas: $\mathrm{VIC}=100-(\%$ de aves mortas) e IEP = (PV x VC) / (I x CA $) \times 100$, em que: PV é o peso vivo das aves $(\mathrm{kg})$, VC é a viabilidade criatória (\%), I é a idade em dias e CA é a conversão alimentar.

No $21^{\circ}$ dia, duas aves com peso mais próximo da média da unidade experimental $( \pm 10 \%)$ foram sacrificadas, após permanecerem 12 horas em jejum, para coleta dos órgãos linfoides (timo, bolsa cloacal e baço). Em seguida estes foram secos em papel-toalha e pesados em balança analítica de precisão, para a determinação do peso absoluto e relativo, sendo que este último foi calculado em função do peso vivo da ave em jejum. Posteriormente, as bolsas cloacais foram destinadas ao Laboratório de Patologia Animal, sendo fixados em formol a $10 \%$ neutro, tamponado, desidratados em passagens sucessivas no álcool etílico, em concentrações crescentes, diafanizados em xilol, infiltrados e incluídos em parafina. Em seguida, foram submetidas à microtomia, obtendo-se cortes histológicos com espessura de $5 \mu \mathrm{m}$, que foram corados pela hematoxilina-eosina (Luna, 1968).

A porcentagem do córtex do folículo linfoide bursal foi determinado pelo analisador de imagem computadorizado (Leica Qwin D-1000, versão 4.1, Cambridge, UK) sob aumento de 100X. Para isso foram utilizados 10 folículos bursais completos, de modo que o corte passava pela região central (Muniz et al., 2006).

O experimento continuou até o $41^{\circ}$ dia, quando foi finalizado. Cinco aves foram selecionadas, conforme critérios adotados aos 21 dias de idade, para avaliação dos parâmetros biométricos dos órgãos linfoides, digestivos e coração; peso das penas e determinação do rendimento de carcaça e cortes nobres (peito, coxa e sobrecoxa).

As análises estatísticas das variáveis estudadas foram realizadas utilizando-se o programa SAEG (Sistema para Análises Estatísticas e Genéticas). A estimativa do melhor nível de adição de cromo orgânico foi estabelecida por meio de modelos de regressão polinomial e/ou descontínuo "Linear Response Plateau" - LRP.

\section{Resultados e discussão}

As médias de temperatura registradas no interior do galpão apresentaram máxima de $37,3^{\circ} \mathrm{C} \pm 1,6$ e mínima de $27,68^{\circ} \mathrm{C}$ $\pm 0,69$; umidade relativa de $55,47 \pm 14,67$ e índice de temperatura do globo e umidade (ITGU) de 83,39 para o período de 21 dias. Para o período de 1 a 41 dias, obtiveram-se as temperaturas de máxima $33,6{ }^{\circ} \mathrm{C} \pm 2,7$ e mínima de $25,22{ }^{\circ} \mathrm{C} \pm 1,32$; umidade relativa de $60,81 \pm 14,01$ e ITGU de 80 . De acordo com Tinôco et al. (2004), a faixa de temperatura ideal para aves nas fases de crescimento e final é de 26 a $15^{\circ} \mathrm{C}$, respectivamente. Desta forma, a temperatura no interior do galpão estava acima do ideal para as duas fases do ciclo produtivo das aves, o que caracterizou um ambiente de estresse por calor. Medeiros et al. (2005) verificaram que o ITGU entre 69 e 77 caracteriza um ambiente de conforto térmico para as aves que apresentam maior produtividade e índices zootécnicos.

No período de 1 a 21 dias os níveis de suplementação do cromo orgânico não influenciaram o ganho de peso e o consumo de ração das aves (Tabela 1$)$. No entanto, influenciaram $(P<0,01)$ de forma quadrática a conversão alimentar dos animais, segundo a equação: $Y=1,67-0,00016 x+0,00000012 x^{2}\left(r^{2}=0,976\right)$, que melhorou até o nível estimado de 667 ppb de cromo orgânico/ $\mathrm{kg}$ de ração, correspondendo a um consumo de $0,94 \mathrm{mg}$ de cromo-metionina/dia. Os resultados para conversão alimentar deste estudo diferenciam-se dos encontrados por Silva e Murakami (2007) Vaz et al. (2009). No entanto, corroboram com os encontrados por Sahin et al. (2001) que observaram uma melhor eficiência alimentar para os frangos de corte suplementados com picolinato de cromo. A divergência entre resultados pode estar relacionada com o ambiente a que os animais foram submetidos, tendo como exemplo, o uso de calor crônico em câmaras bioclimáticas, que, segundo Souza (2008), 
causa maior dificuldade de adaptação pelas aves, que o calor cíclico. Neste contexto, Balnave (2004) relata que as aves se adaptam melhor às temperaturas elevadas que ocorrem durante o dia, quando a temperatura da noite cai para $25^{\circ} \mathrm{C}$ ou menos, pois assim elas recuperam o efeito do estresse sofrido nos períodos mais quentes.

A viabilidade criatória não sofreu diferença estatística $(P>0,05)$ entre os níveis de suplementação do cromo orgânico avaliados, diferentemente dos resultados encontrados por Jackson et al. (2008) que observaram que a suplementação da ração com cromo reduziu a mortalidade dos animais.

O índice de eficiência produtiva sofreu influência significativa $(\mathrm{P}<0,05)$, o que demonstra que 700 ppb de cromo orgânico proporcionou melhor índice em comparação aos demais níveis.

Tabela 1: Desempenho de frangos de corte alimentados com diferentes níveis de cromo orgânico nas rações

\begin{tabular}{lcccccc}
\hline & \multicolumn{7}{c}{ Cromo orgânico (ppb) } & \\
\cline { 2 - 5 } \multicolumn{1}{c}{ Variáveis } & 0 & 350 & 700 & 1050 & 1400 & CV (\%) \\
\cline { 2 - 6 } & 1 a 21 dias de idade & & & \\
\hline Consumo de ração & 1,41 & 1,42 & 1,38 & 1,41 & 1,45 & 6,07 \\
Ganho de peso & 0,86 & 0,93 & 0,91 & 0,92 & 0,86 & 8,00 \\
Conversão alimentar * & 1,63 & 1,53 & 1,53 & 1,55 & 1,68 & 4,79 \\
Viabilidade criatória & 99,03 & 98,02 & 99,08 & 98,08 & 98,97 & 1,45 \\
Índice de eficiência produtiva & $252,2^{\text {ab }}$ & $274,5^{\text {ab }}$ & $279,1^{\text {a }}$ & $270,1^{\text {ab }}$ & $243,7^{\mathrm{b}}$ & 5,95 \\
\hline & 1 a 41 dias de idade & & & \\
\hline Consumo de ração & 4,18 & 4,11 & 4,02 & 4,05 & 4,19 & 6,15 \\
Ganho de peso & 2,41 & 2,43 & 2,46 & 2,47 & 2,53 & 3,88 \\
Conversão alimentar & 1,74 & 1,69 & 1,64 & 1,64 & 1,66 & 5,45 \\
Viabilidade criatória & 96,65 & 93,66 & 95,85 & 96,31 & 95,92 & 3,20 \\
Índice de eficiência produtiva & 349,0 & 329,1 & 357,5 & 359,6 & 347,7 & 9,66 \\
\hline
\end{tabular}

* Efeito quadrático $P<0,05$.

${ }^{1}$ Medias seguidas por letras diferentes na mesma linha diferem significativamente pelo Teste de Tukey $(\mathrm{P}<0,05)$.

No período total, 1 a 41 dias de idade, não se observou efeito entre os níveis de suplementação do cromo orgânico sobre o ganho de peso, consumo de ração, a conversão alimentar, viabilidade criatória e índice de eficiência produtiva $(P>0,05)$. Aves mantidas em estresse por calor cíclico podem se adaptar consumindo menos ração durante o dia, nos períodos de maior temperatura, aumentando a ingestão de alimentos à noite, sem alterar as taxas de mortalidade e consequentemente a viabilidade criatória e índice de eficiência produtiva (Ain Baziz et al., 2006).

Não houve efeito $(P>0,05)$ dos níveis de suplementação de cromo na ração sobre o rendimento de carcaça e de cortes nobres (Tabela 2). Resultados semelhantes foram encontrados por Anandhi et al. (2006) e Souza et al. (2010), que não verificaram efeito da inclusão de cromo sobre o rendimento de carcaça e cortes nobres de frangos de corte.
Tabela 2: Rendimento de carcaça e de cortes nobres de frangos de corte alimentados com diferentes níveis de cromo orgânico nas rações, aos 41 dias de idade

\begin{tabular}{lcccccc}
\hline & \multicolumn{5}{c}{ Cromo orgânico (ppb) } & \\
\cline { 2 - 6 } \multicolumn{1}{c}{ Variáveis (\%) } & 0 & 350 & 700 & 1050 & 1400 & CV $(\%)$ \\
\hline Carcaça & 82,68 & 83,82 & 83,33 & 84,00 & 82,35 & 1,12 \\
Coxa & 13,37 & 12,81 & 13,48 & 12,71 & 12,71 & 4,64 \\
Peito & 27,51 & 29,30 & 28,48 & 28,42 & 29,06 & 4,12 \\
Sobrecoxa & 11,59 & 13,03 & 12,15 & 12,77 & 12,29 & 11,59 \\
\hline
\end{tabular}

Não foi verificado influência $(P>0,05)$ dos níveis de cromo orgânico sobre o peso absoluto e relativo do fígado, moela, intestino e coração dos frangos de corte abtidos aos 41 dias de idade (Tabela 3). Estes resultados estão em consonância com os reultados encontrados por Anandhi et al. (2006), que trabalharam com 250, 500 e 750 ppb e não verificaram efeito da inclusão de cromo sobre o peso e porcentagem de coração, fígado e moela.

Em contrapartida, diferem dos encontrados por Sahin et al. (2003), ao observarem que a suplementação da dieta para frangos com picolinato de cromo $(400 \mathrm{mg} / \mathrm{kg}) \mathrm{em}$ ambientes de temperatura elevada (32 ${ }^{\circ} \mathrm{C}$ ) propiciou efeito positivo sobre o peso do fígado, coração, pâncreas e moela, ocorrendo melhora efetiva na prevenção do estresse calórico. Por outro lado Ribeiro et al. (2001) observaram que os pesos relativo e absoluto do intestino, moela, fígado e coração são menores nas aves submetidas a estresse por calor prévio. Neste estudo, o peso dos órgãos internos das aves mantiveram-se dentro do padrão normal da linhagem, mesmo em condição de estresse por calor ciclico em ambiente natural. Provavelmente, devido ao fato de as temperaturas nos períodos noturnos terem sido menores, foi suficiencte para evitar perda de peso dos órgãos internos, embora não tenha se evidenciado efeito da suplementação com cromo orgânico, esta constatação, em parte, encontra-se de acordo com Balnave (2004), ao admitir que baixas temperaturas noturnas podem recuperar o efeito do estresse sofrido nos períodos mais quentes do dia.

Constatou-se que o peso relativo das penas sofreu influência singnificativa pela suplementação do cromo orgânico $(P \leq 0,05)$. De acordo com Campos et al. (2001), aves com menor peso de penas têm maior relação heterófilo:linfócito, o que indica maior estresse; assim, neste estudo os animais que receberam maior nivel de cromo orgânico na dieta demonstraram melhor resposta em comparação às demais aves.

A suplementação do cromo orgânico não influenciou $(P>0,05)$ a biometria dos órgãos linfoides das aves, aos 21 e 41 dias de idade (Tabela 4). Estes resultados não comprovaram os 
Tabela 3: Pesos absoluto e relativo de órgãos digestivos e coração e penas de frangos de corte alimentados com diferentes níveis de cromo orgânico nas rações, aos 41 dias de idade

\begin{tabular}{lllllll}
\hline & \multicolumn{6}{c}{ Cromo orgânico $(\mathrm{ppb})$} \\
\cline { 2 - 7 } Variáveis & 0 & 350 & 700 & 1050 & 1400 & CV(\%) \\
\hline Fígado & 41,50 & 43,00 & 44,00 & 40,50 & 46,25 & 8,67 \\
Moela & 76,25 & 77,50 & 78,50 & 72,25 & 78,50 & 9,44 \\
Intestino & 102,25 & 99,25 & 95,75 & 92,50 & 104,50 & 8,94 \\
Coração & 12,00 & 12,00 & 10,50 & 10,75 & 12,50 & 12,39 \\
Penas & 0,17 & 0,15 & 0,17 & 0,16 & 0,19 & 12,99 \\
\hline & 1,69 & 1,75 & 1,85 & 1,69 & 1,84 & 6,48 \\
\hline Fígado & 3,11 & 3,15 & 3,30 & 3,03 & 3,13 & 8,00 \\
Moela & 4,18 & 4,06 & 4,04 & 3,87 & 4,17 & 8,51 \\
Intestino & 0,49 & 0,49 & 0,45 & 0,45 & 0,49 & 9,06 \\
Coração & $7,24^{\text {ab }}$ & $6,46^{\mathrm{b}}$ & $7,36^{\mathrm{a}}$ & $6,92^{\mathrm{ab}}$ & $7,96^{\mathrm{a}}$ & 10,67 \\
\hline Penas ${ }^{1}$ & &
\end{tabular}

${ }^{1}$ Medias seguidas por letras diferentes na mesma linha diferem significativamente pelo Teste de Tukey $(\mathrm{P}<0,05)$. possíveis efeitos positivos da suplementação de cromo sobre a fisiologia linforrreticular das aves submetidas a estresse por calor, atribuídos à sua possível ação na redução da síntese de corticosterona, conforme proposto por Sahin et al. (2003). Segundo Comptom et al. (1990), a elevação dos corticoides no sangue, ocasionado nos períodos de estresse por calor, acarreta lise de linfócitos imaturos do timo, ocasionando hipotrofia e involução precoce do órgão. Sahin et al. (2003) relataram que o cromo age como inibidor dos efeitos negativos do estresse causado por altas ou baixas temperaturas ambientais, as quais deprimem o sistema imune pela mudança das concentrações hormonais causada nos animais.

Os parâmetros histomorfométricos da bolsa cloacal encontrados neste estudo (Figura 1) demonstram que a suplementação com cromo orgânico para aves estressadas por calor cíclico em ambiente natural altera a resposta aos desafios ambientais impostos ao sistema imune. A maior percentual de córtex dos folículos linfoides da bolsa cloacal de frangos aos 21 dias de idade sugere que os animais tiveram maior potencial de resposta imunológica frente ao ambiente estressante. Guimarães et al. (2003) demonstraram que, em condições de estresse crônico por frio ou calor, a região cortical do folículo linfoide diminui significativamente, mostrando que a bolsa cloacal da ave está sujeita ao efeito do ambiente.

Tabela 4: Pesos absoluto e relativo de órgãos linfoides (bolsa cloacal, baço e timo) de frangos de corte aos 21 e 41 dias de idade, alimentados com diferentes níveis de cromo orgânico nas rações

\begin{tabular}{|c|c|c|c|c|c|c|}
\hline \multirow[b]{2}{*}{ Variáveis } & \multicolumn{6}{|c|}{ Cromo orgânico (ppb) } \\
\hline & 0 & 350 & 700 & 1050 & 1400 & $\mathrm{CV}(\%)$ \\
\hline & \multicolumn{6}{|c|}{21 dias de idade } \\
\hline \multirow[t]{2}{*}{ Peso do animal em jejum (g) } & 779,37 & 813,75 & 827,50 & 813,12 & 831,25 & 2,27 \\
\hline & \multicolumn{6}{|c|}{ Peso absoluto (g) } \\
\hline Bolsa cloacal & 1,59 & 1,66 & 1,97 & 1,67 & 1,94 & $12,29,0$ \\
\hline Timo & 3,17 & 3,55 & 3,04 & 3,47 & 3,67 & 22,1 \\
\hline \multirow[t]{2}{*}{ Baço } & 0,47 & 0,40 & 0,47 & 0,44 & 0,51 & \\
\hline & \multicolumn{5}{|c|}{ Peso relativo (\%) } & \\
\hline Bolsa cloacal & 0,20 & 0,19 & 0,24 & 0,20 & 0,23 & $11,77,0$ \\
\hline Timo & 0,41 & 0,43 & 0,37 & 0,43 & 0,44 & 22,5 \\
\hline \multirow[t]{2}{*}{ Baço } & 0,061 & 0,049 & 0,057 & 0,054 & 0,061 & \\
\hline & \multicolumn{6}{|c|}{41 dias de idade } \\
\hline \multirow[t]{2}{*}{ Peso do animal em jejum (g) } & 2406 & 2469 & 2499 & 2529 & 2542 & 4,69 \\
\hline & \multicolumn{5}{|c|}{ Peso absoluto (g) } & \\
\hline Bolsa cloacal & 3,56 & 3,47 & 3,79 & 3,51 & 4,16 & $30,55,0$ \\
\hline Timo & 6,54 & 6,39 & 6,81 & 7,56 & 7,15 & 43,5 \\
\hline \multirow[t]{2}{*}{ Baço } & 2,27 & 2,03 & 2,27 & 2,28 & 2,19 & \\
\hline & \multicolumn{5}{|c|}{ Peso relativo (\%) } & \\
\hline Bolsa cloacal & 0,15 & 0,20 & 0,15 & 0,14 & 0,16 & $29,63,0$ \\
\hline Timo & 0,20 & 0,37 & 0,27 & 0,30 & 0,28 & 40,4 \\
\hline Baço & 0,095 & 0,082 & 0,090 & 0,090 & 0,087 & \\
\hline
\end{tabular}






\section{Conclusão}

Recomenda-se a suplementação da dieta com o nível de 700 ppb de cromo-metionina para frangos de corte de 1 a 41 dias de idade, frente a condições de estresse por calor cíclico.

Figura 1: Porcentagem média da área cortical nos folículos linfoides da bolsa cloacal de frangos de corte aos 21 dias de idade suplementados com cromo orgânico

\section{Referências}

ANANDHI, M. et al. Dietary inclusion of organic chromium on production and carcass characteristics of broilers. International Journal of Poultry Science, v. 9, p. 880-884, 2006.

AIN BAZIZ, H.A. et al. Chronic heat exposure enhances fat deposition and modifies muscle and fat partition in broiler carcasses. Poultry Science, v. 75, p. 505-513, 2006.

BALNAVE, D. Challenges of accurately defining the nutrient requeriments of heat-stressed poultry. Poultry Science, v. 83, p. 5-14, 2004.

BUFFINGTON, D.E. et al. Black globe-humidity index (BGHI) as comfort equation for dairy cows. Transaction of the ASAE, v. 24, p.711-714, 1981.

CAMPOS, J.L. et al. Association between plumage condition and fear and stress levels in Five breeds of chickens. Poultry Science, v. 80, n. 4, p. 549-552, 2001.

COMPTON M.M. et al. Glicocorticoid Activation of Deoxyribonucleic Acid Degradation in Bursal Lymphocytes. Poultry Science, v. 69, p.1292-1298, 1990.

GUIMARÃES, E.B. et al. Porcentagem de parênquima e índice apoptótico da bolsa cloacal em frangos de corte em ambiente de conforto e estresse térmico. Arquivo

Brasileiro de Medicina Veterinária e Zootecnia, p. 178-186, 2003.

JACKSON, A.R. et al. The Effect of Chromium Propionate on Growth Performance and Carcass Traits in Broilers. Applied Poultry Science, v. 17, p. 476-481, 2008.

LUNA, L.G. Manual of histologic staining methods of the Armed Forces Institute of Pathology. 3 rd ed. New York: MacGraw-will, 1968, 258p.

MEDEIROS, C.M. et al. Efeitos da temperatura, umidade relativa e velocidade do ar em frangos de corte. Revista Engenharia na Agricultura, v.13, p. 277-286, 2005.

MUNIZ, E.C. et al. Histomorphology of bursa of Fabricius: effects of stock densities on commercial broilers. Revista Brasileira de Ciência Avícola, p. 217-220 2006.

RIBEIRO, A.M.L. et al. Effects of 2-hydroxy-4-(methylthio)butanoic acid and DL-Methionine on broiler performance and compensatory growth affer exposure to two different environmental temperatures. Journal Appied. Poultry Research, v.10, n. 4, p. 419-426, 2001.
RIBEIRO, A.M.L. et al. Suplementação de vitaminas e minerais orgânicos e sua ação sobre a imunocompetência de frangos de corte submetidos a estresse por calor. Revista Brasileira de Zootecnia, v. 37, p. 636-644, 2008.

ROSTAGNO, H.S. et al. Composição de alimentos e exigências nutricionais (Tabelas Brasileiras para aves e suínos). Viçosa, MG: UFV, Departamento de Zootecnia, p.141, 2000.

SAHIN, K. et al. Effects of dietary chromium picolinate supplementation on performance and plasma concentrations of insulin and corticosterone in laying hens under low ambient temperature. Journal of Animal Physiology and Nutrition, v. 85, p.142-147, 2001.

SAHIN, K. et al. Effects of chromium and ascorbic acid supplementation o growth, carcass traits, serum metabolities, and antioxidant status of broiler chickens reared at a high environmental temperature $\left(32^{\circ} \mathrm{C}\right)$. Nutrition Research, v. 23, p. 225-238, 2003.

SILVA, L.M.G.; MURAKAMI, A. C. Uso do cromo na alimentação de frangos de corte. Revista Brasileira de Zootecnia, v. 36, n. 4, p.1026-1030, 2007.

SOUZA, L.F.A. Exposição crônica e cíclica ao calor em frangos de corte: desempenho, metabolização dos nutrientes e atividade de enzimas pancreáticas. 2008. 62 f. Dissertação (Mestrado em Zootecnia) - Faculdade de Ciências Agrárias e Veterinárias/ Universidade Estadual de São Paulo, Jaboticabal.

SOUZA, L. M. G. et al. Influência do cromo no desempenho, na qualidade da carne e no teor de lipídeos no plasma sanguíneo de frangos de corte. Revista Brasileira de Zootecnia, v. 39, n. 4, p. 808-814, 2010.

TANYOLAÇ, A. Özel Histoloji . Yorum Basın Yayın Sanayi Ltd., Ankara, p. 162-165, 1993.

TINÔCO, I.F.F. et al. Placas porosas utilizadas em sistemas de resfriamento evaporativo. Revista Engenharia na Agricultura, v.12, n. 1, p. 17-23, 2004.

VAZ, R.G.M. et al. Níveis de cromo orgânico em rações para frangos de corte mantidos sob estresse por calor no período de um a 42 dias de idade. Arquivo Brasileiro de Medicina Veterinária e Zootecnia, v. 61, n. 2, p. 484-490, 2009. 